\title{
Study of clinical profile of dermatophytosis in a tertiary care center as per ECTODERM guidelines
}

\author{
Shitij Goel ${ }^{1}$, Shivam $^{2}$, Azra Ferheen Chaudhary ${ }^{3}$ \\ ${ }^{1}$ Professor, ${ }^{2,3}$ Resident, Department of Dermatology, Sharda Hospital (School of Medical Sciences and Research, \\ Sharda University) Greater Noida, Uttar Pradesh, India
}

Background: Dermatophytic infections are one of the most common skin infections encountered by dermatologists. A recent increase in incidence has been seen over the last few years with substantial change in the clinical profile of patients. Recently a group of dermatology experts published Expert Consensus on The Management of Dermatophytosis in India (ECTODERM India). The group agreed upon various definitions with respect to current dermatophytosis epidemic as well as gave recommendations for investigations and management. Clinical profile of dermatophytosis was done in present study on the basis of definitions agreed upon by ECTODERM consensus group. Aims and Objective: To assess the clinical profile, prevalence and severity of dermatophytic infection in study population. Materials and Methods: Cross-sectional observational study was conducted at out-patient department of Dermatology in, Sharda hospital, Greater Noida. A total of 317 patients presenting with clinical diagnosis of dermatophytosis were included in the study. Results: A total of 317 patients were recruited in the study, out of which 213 were males $(67.2 \%)$. The most common age group presenting with superficial dermatophytosis was 21-30 years. Majority of the patient presented with chronic dermatophytosis with duration more than 6 months $(76.6 \%)$ while more than 3 lesions of tinea were observed in $76.6 \%$ cases. 191 patients $(60 \%)$ had moderate to severe involvement with more than $3 \%$ of BSA involved. Family members presenting with similar complaints were seen in $39 \%$ cases. Majority of patients (76 \%) studies had received previous treatment topical, systemic or both. 62 patients presented with recurrence of disease within 6 weeks of complete antifungal treatment $(19.6 \%)$. Conclusion: Our study concludes that dermatophytosis still remain a challenging issue for dermatologists. Chronicity of infection, moderate to severe BSA involvement and involvement of family members in a good proportion of our study cases were the main findings of our study.

Key words: Dermatophytosis; ECTODERM India guidelines

\section{INTRODUCTION}

Dermatophytes are filamentous fungi in the genera Trichophyton, Microsporum and Epidermophyton. Dermatophytic infections are common worldwide and they are prevailing causes of infection of the skin, hair, and nails. ${ }^{1}$ These infections lead to a variety of clinical manifestations, such as tinea pedis, tinea corporis, tinea cruris, tinea capitis, and tinea unguium. A diagnosis of
Access this article online

Website:

http://nepjol.info/index.php/AJMS

DOI: 10.3126/ajms.v12i10.37653

E-ISSN: 2091-0576

P-ISSN: 2467-9100

Copyright (c) 2021 Asian Journal of Medical Sciences

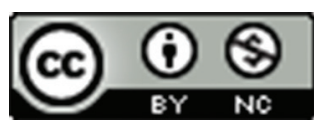

This work is licensed under a Creative Commons Attribution-NonCommercial 4.0 International License. 
Currently, dermatologists across India are inundated with cases of dermatophytosis presenting with unusual large lesions, ring within ring lesions, multiple site lesions (tinea cruris et corporis), and corticosteroid modified lesions, making diagnosis a difficult bet. This changed face of dermatophytosis has created a real panic among dermatologists. ${ }^{3}$

As per various studies prevalence of dermatophytosis in India ranges from 36.6-78.4 \%. ${ }^{4}$ Recently a group of dermatology experts published Expert Consensus on The Management of Dermatophytosis in India (ECTODERM India). ${ }^{5}$ The group agreed upon various definitions with respect to current dermatophytosis epidemic as well as gave recommendations for investigations and management. Various agreed upon definitions are as under-

a) Dermatophytosis: Dermatophytosis (ringworm or tinea) is an infection of the skin or skin derivatives, caused by fungi known as dermatophytes leading to erythema, small papules, plaques, vesicles, fissures, and scaling having ring-like morphology.

b) Chronic Dermatophytosis: Dermatophytosis is considered to be chronic when the patients who have suffered from the disease for more than 6 months to 1 year, with or without recurrence, in spite of being adequately treated.

c) Recurrent Dermatophytosis: Dermatophytosis is considered to be recurrent when there is re-occurrence of the disease (lesions) within few weeks ( $<6$ weeks) after completion of the treatment.

d) Relapse: Relapse denotes the occurrence of dermatophytosis (lesions), after a longer period of infection-free interval (6-8 weeks) in a patient who has been cured clinically.

e) BSA (Body Surface Area): The area of outstretched palm from the wrist to the tip of the fingers can be considered roughly $1 \%$ of the body surface area. Less than $3 \%$ can be counted mild, $3-10 \%$ as moderate, and more than $10 \%$ as severe, in terms of the extent of involvement.

\section{MATERIALS AND METHODS}

Ethical clearance was obtained by Institutional Ethics Committee before starting the study, Ref. No. SU/ SMS\&R/76-A/2020/29. This cross-sectional observational study was conducted at out-patient department of Dermatology in a tertiary Care teaching hospital of northern India. Total of 317 patients presenting with clinical diagnosis of dermatophytosis, who were willing to participate in the study were enrolled between June 2020 to October 2020. Informed consent was taken from all the patients.

\section{INCLUSION CRITERIA}

- Patients with age group between 18 to 60 years.

- Patients presenting for the first time to our OPD, having clear clinical diagnosis of dermatophytosis as per ECTODERM guideline were selected.

- Patients who gave written and informed consent for participation in the study.

\section{EXCLUSION CRITERIA}

- Patients having onychomycosis, candidial intertrigo, pityriasis versicolor were not included.

- Doubtful cases like tinea incognito were not included.

- Pregnant/lactating women.

- Immuno-compromised state like HIV, Diabetes.

\section{Study method}

As per the various definitions of ECTODERM Guidelines, detailed history was taken in all the patients with respect to total duration, treatment taken, duration of disease clearance after completing the treatment in past, family history of similar disease etc. Detailed examination was done to note down number of lesions and body sites involved. Body Surface Area was calculated considering area of outstretched palm from the wrist to tip of fingers constituting roughly $1 \%$.

\section{RATIONALE OF STUDY}

- Our study was based on Expert Consensus guidelines (ECTODERM)

- The study will help us to understand and classify clinical profile of dermatophytosis in present scenario and also standardize care, provide guidance on the management, and assist in clinical decision-making.

\section{AIM AND OBJECTIVE}

- The aim of the study was to assess the clinical profile of dermatophytic infection as per ECTODERM India guidelines.

- To identify the prevalence of infection among different age groups.

- To find out the extent of dermatophytic infection among family members.

- To grade the severity of dermatophytic infection in study population.

\section{Statistical analysis}

All the data obtained was analyzed statistically using Microsoft excel 2007, SPSS. Student t-test (unpaired and 
paired) and chi-square tests were used where appropriate to test the significance of data.

\section{RESULTS}

Our study assessed burden of Dermatophytosis in a tertiary care hospital with respect of ECTODERM India guidelines. A total of 317 patients were recruited in our study, out of which majority were male patients $213(67.2 \%)$ and female patients were $104(32.8 \%)$ (Table 1). Most of the patients were from a rural background. The most common age group presenting with superficial dermatophytosis belongs to age group of 21 - 30 years followed by age group 41-50 years (19.2\%) (Table 2). Majority of the patient presented with chronic disease with duration more than 6 months $(243 ; 76.6 \%)$ (Table 3) and with more than 3 lesions seen in 243 (76.6\%) cases (Table 4). Multiple areas were involved mainly being groin, abdomen and buttocks. Up to 191 patients (60\%)

\begin{tabular}{lcccc}
\multicolumn{5}{l}{ Table 1: Age and sex frequency } \\
\hline Gender & $\begin{array}{c}\text { No of } \\
\text { Patients }\end{array}$ & Percent & $\begin{array}{c}\text { Valid } \\
\text { Percent }\end{array}$ & $\begin{array}{c}\text { Cumulative } \\
\text { Percent }\end{array}$ \\
\hline Female & 104 & 32.8 & 32.8 & 32.8 \\
Male & 213 & 67.2 & 67.2 & 100.0 \\
Total & 317 & 100.0 & 100.0 & \\
\hline
\end{tabular}

Table 2: Number of patient age group wise

\begin{tabular}{lcccc}
\hline Age Group & $\begin{array}{c}\text { No of } \\
\text { Patients }\end{array}$ & Percent & $\begin{array}{c}\text { Valid } \\
\text { Percent }\end{array}$ & $\begin{array}{c}\text { Cumulative } \\
\text { Percent }\end{array}$ \\
\hline $11-20$ & 43 & 13.6 & 13.6 & 13.6 \\
$21-30$ & 127 & 40.1 & 40.1 & 53.6 \\
$31-40$ & 52 & 16.4 & 16.4 & 70.0 \\
$41-50$ & 61 & 19.2 & 19.2 & 89.3 \\
$51-60$ & 18 & 5.7 & 5.7 & 95.0 \\
$61-70$ & 16 & 5.0 & 5.0 & 100.0 \\
Total & 317 & 100.0 & 100.0 & \\
\hline
\end{tabular}

\begin{tabular}{lcccc} 
Table 3: Duration of disease & & \\
\hline Duration & $\begin{array}{c}\text { No of } \\
\text { Patients }\end{array}$ & Percent & $\begin{array}{c}\text { Valid } \\
\text { Percent }\end{array}$ & $\begin{array}{c}\text { Cumulative } \\
\text { Percent }\end{array}$ \\
\hline$<6$ months & 74 & 23.3 & 23.3 & 23.3 \\
$>1$ year & 81 & 25.6 & 25.6 & 48.9 \\
6 months -1 & 162 & 51.1 & 51.1 & 100.0 \\
years & 317 & 100.0 & 100.0 & \\
Total & & & & \\
\hline
\end{tabular}

\begin{tabular}{lcccc}
\multicolumn{4}{l}{ Table 4: Number of lesions } \\
\hline Lesions & $\begin{array}{c}\text { No of } \\
\text { Patients }\end{array}$ & Percent & $\begin{array}{c}\text { Valid } \\
\text { Percent }\end{array}$ & $\begin{array}{c}\text { Cumulative } \\
\text { Percent }\end{array}$ \\
\hline$<3$ & 61 & 19.2 & 19.2 & 19.2 \\
$>5$ & 98 & 30.9 & 30.9 & 50.2 \\
$3-5$ & 158 & 49.8 & 49.8 & 100.0 \\
Total & 317 & 100.0 & 100.0 & \\
\hline
\end{tabular}

had moderate to severe involvement with more than 3\% of BSA involved (Table 5). Family members presenting with similar complaints were seen in $124(39 \%)$ cases (Table 6). Majority of patients 243 (76\%) had history of some form of previous treatment either topical or systemic or both (Table 7). History of recurrence of symptoms within 6 weeks was seen in $62(19.6 \%)$ patients (Table 8).

\section{DISCUSSION}

Superficial mycoses form a large fraction of ailments in patients attending the Skin outpatient department at any center. It is an indisputable fact that there is an increase in the prevalence of dermatophytosis over the past $4-5$ years across the country. The present study is based on the "Expert Consensus on The Management of Dermatophytosis in India (ECTODERM India)" study ${ }^{5}$ where eleven experts

\begin{tabular}{lcccc}
\multicolumn{5}{l}{ Table 5: Body surface area involved } \\
\hline BSA & $\begin{array}{c}\text { No of } \\
\text { Patients }\end{array}$ & Percent & $\begin{array}{c}\text { Valid } \\
\text { Percent }\end{array}$ & $\begin{array}{c}\text { Cumulative } \\
\text { Percent }\end{array}$ \\
\hline$<3$ & 126 & 39.7 & 39.7 & 39.7 \\
$>10$ & 51 & 16.1 & 16.1 & 55.8 \\
$3-10$ & 140 & 44.2 & 44.2 & 100.0 \\
Total & 317 & 100.0 & 100.0 & \\
\hline
\end{tabular}

\begin{tabular}{lcccc}
\multicolumn{4}{l}{ Table 6: Number of family members involved } \\
\hline Family & $\begin{array}{c}\text { No of } \\
\text { Patients }\end{array}$ & Percent & $\begin{array}{c}\text { Valid } \\
\text { Percent }\end{array}$ & $\begin{array}{c}\text { Cumulative } \\
\text { Percent }\end{array}$ \\
\hline$<3$ & 113 & 35.6 & 35.6 & 35.6 \\
0. & 193 & 60.9 & 60.9 & 96.5 \\
$3-5$ & 11 & 3.5 & 3.5 & 100.0 \\
Total & 317 & 100.0 & 100.0 & \\
\hline
\end{tabular}

\begin{tabular}{|c|c|c|c|c|}
\hline $\begin{array}{l}\text { Previous } \\
\text { treatment } \\
\text { taken }\end{array}$ & $\begin{array}{c}\text { No of } \\
\text { Patients }\end{array}$ & Percent & $\begin{array}{c}\text { Valid } \\
\text { Percent }\end{array}$ & $\begin{array}{c}\text { Cumulative } \\
\text { Percent }\end{array}$ \\
\hline Topical & 117 & 36.9 & 36.9 & 100.0 \\
\hline Oral & 42 & 13.2 & 13.2 & 63.1 \\
\hline Both & 84 & 26.5 & 26.5 & 26.5 \\
\hline None & 74 & 23.3 & 23.3 & 49.8 \\
\hline Total & 317 & 100.0 & 100.0 & \\
\hline
\end{tabular}

\begin{tabular}{lcccc}
\multicolumn{4}{l}{ Table 8: Number of patients with recurrence } \\
\hline Recurrence & $\begin{array}{c}\text { No of } \\
\text { Patients }\end{array}$ & Percent & $\begin{array}{c}\text { Valid } \\
\text { Percent }\end{array}$ & $\begin{array}{c}\text { Cumulative } \\
\text { Percent }\end{array}$ \\
\hline < 6 Weeks & 62 & 19.6 & 19.6 & 19.6 \\
> 6 Weeks & 15 & 4.7 & 4.7 & 24.3 \\
Not Applicable & 240 & 75.7 & 75.7 & 100.0 \\
Total & 317 & 100.0 & 100.0 & \\
\hline
\end{tabular}


in the field of clinical dermatology and mycology participated in the modified Delphi process consisting of two workshops and five rounds of questionnaires, elaborating definitions, diagnosis and management. The expert panel achieved consensus on the definitions for the various terminologies like dermatophytosis, naive infection, chronic infection, recurrent infection or relapse of infection.

In this study of profile of dermatophytosis in a tertiary care center, ${ }^{6}$ authors have found that chronic dermatophytosis was seen in $68 \%$ cases; tinea corporis was the most common presentation.

There was a high prevalence among males in this study with Male to female ratio of 2.04:1. High incidence of superficial mycoses in males has been reported by Grover and $\operatorname{Roy}^{7}(81 \%)$, Singh S et al., ${ }^{8}(61.1 \%)$, Oliveira et al., ${ }^{9}(64.45 \%)$, and Vasu et al. ${ }^{10}(72.4 \%)$. Philpot suggested that males may be more vulnerable to infection than females probably due to higher exposure to infection in the army, in the schools, in the greater use of public bath and sporting activities; and the type of shoes and socks they use. ${ }^{13}$ Majority of the patients $(40 \%)$ were in age group 21-30 years. This was in concordance with other studies where most common age group affected was in second decade. ${ }^{11,12}$ Tinea corporis was the most common type observed in the study as observed with few other Indian studies. ${ }^{12,14}$ However in a north eastern ${ }^{7}$ study tinea pedis was the most common infection.

In the present study majority of the patients (50\%) had chronic disease and recurrence of symptoms. This aspect can be related to the injudicious over the counter use of topical steroids. The cutaneous inflammatory response that the skin mounts to resist and limit the fungal infection is majorly suppressed with use of steroids. This temporary suppression of the hostinduced inflammation leads to ineffective elimination of the dermatophyte, and the process becomes chronic and also widespread. This substantial change in the clinical profile of patients with an increase in the number of chronic, recurrent, or recalcitrant dermatophytosis in India is alarming, and the paucity of evidence is disheartening.

\section{LIMITATIONS OF THE STUDY}

The present study has the following limitations. Diagnostic test was not done to confirm the diagnosis. The significant morbidity, mortality and healthcare-related costs due to fungal infections deserve detailed epidemiological data. However, we believe that the present estimates are important and will hopefully lead to well-designed epidemiological studies in future.

\section{CONCLUSION}

Comparison of studies done on superficial fungal infections in different studies done during different time frames have revealed an increasing trend of dermatophytosis. We however, need larger epidemiological studies to further bolster our nationwide observation of the alarming increase in its incidence as well as the prevalence.

\section{ACKNOWLEDGEMENT}

The authors appreciate the support of Dr Khushboo Arora, former Senior Resident at Department of Dermatology, Sharda Hospital for her valuable inputs.

\section{REFERENCES}

1. Havlickova B, Czaika VA and Friedrich M. Epidemiological trends in skin mycoses worldwide. Mycoses. 2008; 51 Suppl 4:2. https://doi.org/10.1111/j.1439-0507.2008.01606.x

2. Narasimhalu CR, Kalyani M and Somendar S. A cross-sectional, clinico-mycological research study of prevalence, aetiology, speciation and sensitivity of superficial fungal infection in Indian patients. J Clin Exp Dermatol Res. 2016; 7:324.

https://doi.org/10.4172/2155-9554.1000324

3. Bindu V and Pavithran K. Clinico-mycological study of dermatophytosis in Calicut. Indian J Dermatol Venereol Leprol. 2002; 68:259-261.

4. Dogra $S$ and Narang T. Emerging atypical and unusual presentations of dermatophytosis in India. Clin Dermatol Rev. 2017; 1:12-18.

https://doi.org/10.4103/CDR.CDR_39_17

5. Rajagopalan M, Inamadar A, Mittal A, Autar K. Miskeen, Srinivas $\mathrm{CR}$, Sardana K, et al. Expert Consensus on The Management of Dermatophytosis in India (ECTODERM India). BMC Dermatology. 2018; 18: Article number: 6. https://doi.org/10.1186/s12895-018-0073-1

6. Vineetha M, Sheeja S, Celine MI and Saranya Das S. Profile of Dermatophytosis in a Tertiary Care Center. Indian J Dermatol. 2018; 63(6): 490-495.

https://doi.org/10.4103/0019-5154.265814

7. Grover S and Roy P. Clinico-mycological profile of superficial mycosis in a hospital in North East India. Med J Armed Forces India. 2003; 59(2):114-116. https://doi.org/10.1016/S0377-1237(03)80053-9

8. Singh $S$ and Beena PM. Profile of dermatophyte infections in Baroda. Indian Journal of Dermatology Venereology and Leprology. 2003; 69: 281-283.

9. Oliveira JAA, Barros JA, Cortez ACA and Oliveira JSRL. Superficial mycoses in the city of Manaus/AM. An Bras Dermatol. 2006; 238- 243.

https://doi.org/10.1590/abd1806-4841.20141783

10. Vasu DRBH. Incidence of dermatophytosis in Warangal, A.P. India. Indian Journal of Medical Research. 1966; 54: 468-474. 
11. Sudha $M$, Ramani $C P$ and Anandan $H$. Prevalence of dermatophytosis in patients in a tertiary care centre. Int $\mathrm{J}$ Contemp Med Res. 2016;3: 2399-2401. https://www.ijcmr.com/ uploads/7/7/4/6/77464738/ijcmr_835_aug_10.pdf

12. Noronha TM, Tophakhane RS and Nadiger S. Clinicomicrobiological study of dermatophytosis in a tertiary-care hospital in North Karnataka, Indian Dermatol Online J. 2016; 264-271. https://doi.org/10.4103/2229-5178.185488

13. Philpot CM. Some aspects of the epidemiology of tinea. Mycopathologia. 1997; 3:62.

https://doi.org/10.1007/BF00491990

14. Das K, Basak S and Ray S. A study on superficial fungal infection from West Bengal: A brief report. J Life Sci. 2009; 1:51-55. https://doi.org/10.1080/09751270.2009.11885134

\section{Author's Contribution:}

SG-Concept and design of the study; manuscript preparation and enrolled patients; S- Interpreted the results, enrolled patients and reviewed the literature; AFC- Statistical analyses, enrolled patients and revision of the manuscript.

\section{Work attributed to:}

Department of Dermatology, Sharda Hospital, Greater Noida, Uttar Pradesh, India.

Orcid ID:

Dr. Shitij Goel- (D) https://orcid.org/0000-0001-5186-507X

Dr. Shivam- https://orcid.org/0000-0002-0155-4748

Dr. Azra Ferheen Chaudhary- (1) https://orcid.org/0000-0001-7497-5212

Source of Funding: None, Conflict of Interest: None. 